\title{
In Response to: Cannabinoid Hyperemesis Syndrome: Diagnosis, Pathophysiology, and Treatment-a Systematic Review
}

\author{
Joanne C. Routsolias ${ }^{1}$
}

Received: 11 February 2017 / Revised: 12 February 2017 / Accepted: 22 February 2017 /Published online: 9 March 2017

(C) American College of Medical Toxicology 2017

I read with great interest Sorensen et al.'s review article on Cannabinoid Hyperemesis Syndrome (CHS) in the March issue of Journal of Medical Toxicology [1]. I completely agree it is a challenging problem for which there is no current consensus on optimal treatment for these patients. While the authors discussed several traditional treatment options, I do not think they gave haloperidol enough attention. I thank them for briefly mentioning a couple of our case reports in their review, but since then, we have had more success using haloperidol. Our emergency department (ED) experience is similar to others who report CHS is unresponsive to conventional pharmacologic anti-emetics [2, 3]. Failure of standard ED medications results in additional testing and hospital admission when clinicians are afraid they are missing something [4]. We recently published a case series of patients that improved dramatically with haloperidol after failing standard medications, all patients ended up going home from the ED [5]. That compelling case series was not referenced in the otherwise excellent review [1]. Although the exact mechanism for CHS remains unclear, animal data demonstrate complex interactions between dopamine and cannabinoid type 1 signaling, a potential mechanism for haloperidol success in patients with CHS, and the reason why we started using it [6]. Haloperidol also has a long successful history of clinical use for post-operative nausea [7]. Although I am certain haloperidol is unlikely to work in all patients, I am convinced it works often enough to warrant further investigation to determine optimal dosing, optimal

Joanne C. Routsolias

joanne.routsolias@cookcountyhhs.org

1 Clinical PharmD - Emergency Medicine/Toxicology, Cook County Health and Hospitals System, Chicago, IL 60612, USA timing, and the appropriate target patient. Thank you to Sorensen and colleagues for bringing the pharmacologic frustrations of CHS to the attention of readers. I welcome a collaborative prospective study in evaluating all proposed treatment options for CHS to optimize care for this challenging population.

\section{Compliance with Ethical Standards}

Conflicts of Interest None.

Sources of Funding None.

\section{References}

1. Sorensen CJ, Desanto K, Borgelt L, et al. Cannabinoid hyperemesis syndrome: diagnosis, pathophysiology, and treatment - a systematic review. J Med Toxicol. 2016; 3(1):71-87.

2. Sun S, Zimmermann AE. Cannabinoid hyperemesis syndrome. Hosp Pharm. 2013;48(8):650-5.

3. Sullivan S. Cannabinoid hyperemesis. Can J Gastroenterol. 2010;24(5):284-5.

4. Wallace EA, Andrews SE, Garmany CL, Jelley MJ. Cannabinoid hyperemesis syndrome: literature review and proposed diagnosis and treatment algorithm. SMJ. 2011;104(9):659-64.

5. Witsil J, Mycyk MB. Haloperidol, a novel treatment for cannabinoid hyperemesis syndrome. Am J Ther. 2017;24:e64-7.

6. Schulze DR, Carroll FI, McMahon LR. Interactions between dopamine transporter and cannabinoid receptor ligands in rhesus monkeys. Psychopharmacology. 2012;222:425-38.

7. Gan TJ, Meyer T, Apfel CC, et al. Consensus guidelines for managing postoperative nausea and vomiting. Anesth Analg. 2003;97:62-71. 